Revista EJA em Debate

Ano (9). Edição no 15 - jan-jul. 2020

\title{
Salete Valer
}

Doutora em Linguística (Psicolinguística aplicada)

Instituto Federal de Educação, Ciência e Tecnologia de Santa Catarina, Campus FlorianópolisContinente

E-mail: salete.valer@ifsc.edu.br

Orcid: https://orcid.org/0000-0002-9391-3807

\section{Ivelã Pereira}

Doutoranda em Linguística (Sociolinguística)

Instituto Federal de Educação, Ciência e Tecnologia de Santa Catarina, Campus Chapecó

E-mail: ivela.pereira@ifsc.edu.br

Orcid: https://orcid.org/0000-0001-7840-0678

Organizamos o lançamento desta edição da Revista EJA em Debate em meio a um contexto de pandemia mundial, que levou a sociedade ao fechamento físico das salas de aula e a um generalizado distanciamento social. A Educação de Jovens e Adultos, tal como outras modalidades de ensino, passa por um momento de reflexão inescapável, principalmente no que tange ao acesso dos discentes à educação na sociedade desigual em que nos encontramos no Brasil.

Temos percebido, a duras vivências, que o letramento digital não tem sido para todos,tendo em seu bojo uma questão social intrínseca, a qual afeta não somente a construção e acesso de conhecimentos no uso das tecnologias, mas também outros aspectos da vida dos sujeitos. É neste momento histórico, no qual os brasileiros percebem mais claramente nossas reais discrepâncias sociais, desveladas pela imposição da interdição física das escolas, é que lançamos a edição número 15, do primeiro semestre de 2020.

Os textos desta edição da revista foram recebidos em momento anterior à pandemia no Brasil, de modo que não tiveram como tema os desafios que foram impostos a nós, educadores, nesta situação histórica. No entanto, trazem reflexões importantes sobre formação de professores, gestão, políticas públicas e teorias e práticas pedagógicas, que se fazem, agora, ainda mais necessárias. Com isso, ocasionalmente (ou não), os textos desta edição convidam o leitor/educador a pensar sobre temas imprescindíveis a 2020 e seus distanciamentos, como, por exemplo, o letramento digital e uso das tecnologias no contexto da educação de Jovens e Adultos.

Tal temática, talvez marginalizada em relação à modalidade de ensino da EJA, que é foco desta revista, mostrou-se, neste ínterim, de caráter emergencial. Este ano pandêmico, talvez sequer imaginado por muitos de nós, tem mostrado que não é possível mais protelar a discussão sobre o uso de tecnologias e de comunicação no ensino. Assim, o uso de e trabalho com plataformas digitais torna-se não só uma proposta didática, como também uma necessidade fundamental no cotidiano de alunos e professores em distanciamento social.

O momento presente também nos impulsiona a pensar outros momentos históricos em relação à trajetória da Educação de Jovens e Adultos no Brasil. Do mesmo modo, apresentamse novos desafios relacionados à gestão educacional: quais são os impasses no ensinoaprendizagem na EJA que já se apresentaram e hoje se apresentam? Para além disso, os desafios do ensino remoto levam o docente a refletir sobre sua identidade e seu papel como educador, bem como suas implicações no processo de ensino e aprendizagem. 
Trata-se, pois, de tempo propício para (re)pensar e (re)dimensionar estratégias didáticas que visem à promoção da aprendizagem ativa dos alunos, mediante uma educação emancipadora e que lhes propicie autonomia (digital e não digital) na construção do conhecimentos em diversas áreas de ensino.

Na seção Formação de professores, o artigo original Ser professor: sentidos, análises e incertezas de si, do autor Veridiano Maia dos Santos, trata a respeito da identidade docente, a partir de entrevistas individuais e coletivas, complementares entre si, no âmbito da pesquisa qualitativa, com professores do Ensino Fundamental da Educação de Jovens e Adultos no município de Natal/RN, Brasil. Para tanto, ampara-se na Teoria das Representações Sociais e discute o contexto de incertezas no qual os docentes convivem no seu cotidiano escolar, atravessado de sentidos contraditórios e análises sobre o seu fazer pedagógico dentro dessa complexa modalidade. O texto traz à vista questões que afetam o professorado em níveis contrastantes de sabores e dissabores nas suas rotinas escolares, desvelando a compreensão da construção de representações sociais, que se costuram como saberes do senso comum de tais profissionais da educação escolar pública. Os depoimentos dos entrevistados, analisados pelo pesquisador, revelam as representações sociais de professores sobre os alunos jovens e adultos que retornaram ao estudo, traçando reflexões essenciais ao fazer docente daqueles que se dedicam a essa modalidade de ensino.

Em sequência, na seção de Gestão, o artigo original Políticas educacionais: gestão dos impasses do ensino-aprendizagem na perspectiva de docentes e discentes da EJA, dos autores Ruan Carlos dos Santos e Katia Santos, busca identificar os principais impasses e desafios vivenciados pelos professores dessa modalidade de educação em um contexto educativo específico, mediante estudo de caso, pesquisa bibliográfica e de campo. A pesquisa foi realizada, em 2019, nas Unidades Descentralizadas (UD's) do Vale do Rio Tijucas da Secretaria Estadual de Educação de Santa Catarina que atende o Ensino Fundamental $\left(5^{\circ}\right.$ ao $9^{\circ}$ ano) e o Ensino Médio ( $1^{\circ}$ ao $3^{\circ}$ ano) da EJA nos três turnos do dia, e os resultados indicaram alguns caminhos. No decorrer do texto e a partir desses resultados, os pesquisadores defendem a necessidade de se investir em capacitação docente e material didático específico para os alunos da EJA, bem como a emergência de se pensar estratégias que minimizem a evasão dos alunos, além de se buscar uma adaptação dos documentos norteadores do trabalho pedagógico às especificidades do público atendido, com vistas à garantia de melhor qualidade no ensino da Educação de Jovens e Adultos.

Já na seção de Políticas Públicas, o ensaio A trajetória da educação de jovens e adultos no Brasil, de Lenir Keller e Elsbeth Léia Spode Becker, discorre sobre fatos relevantes que compõem a história da Educação de Jovens e Adultos no Brasil por meio de um levantamento documental e bibliográfico da literatura pertinente a políticas públicas, à legislação desde o Brasil Colônia até a atualidade, com a intenção de compreender a evolução da modalidade nos diferentes momentos históricos, além dos seus desdobramentos no campo educacional. A defesa dos autores é no sentido de que o pensamento em prol da EJA e sua qualidade de ensino exigem flexibilidade, maturidade psicológica, criatividade e complexidade cognitiva, na medida em que se busca atender às características e qualidades de desenvolvimento e de cultura dos jovens e adultos, às suas histórias de vida e contextos sociais.

Partindo-se para a seção de Teorias e Práticas Pedagógicas, são apresentados três artigos originais que apresentam discussões educacionais em âmbitos diversos da Educação de Jovens e Adultos, sendo que um deles aborda a questão do uso das tecnologias da informação e comunicação nessa modalidade de ensino, ao passo que os outros dois textos trazem propostas metodológicas de ensino nas áreas de Língua Portuguesa e Química.

O artigo Uma análise da fluência da redação de estudantes do PROEJA auxiliados por blog na educação, de Carlos Emilio Padilla Severo e Viviane Borba Bueno Rodrigues, descreve uma investigação que teve como objetivo apresentar alternativas pedagógicas à aula 
expositiva tradicional no desenvolvimento da fluência da escrita do estudante da educação profissional e tecnológica, na EJA, em aulas de Língua Portuguesa. O trabalho investigativo foi de natureza qualitativa, e os instrumentos utilizados para análise dos resultados foram a observação participativa da pesquisadora, bem como questionários direcionados aos estudantes e docente regente da disciplina já mencionada. Os resultados, conforme revelam os autores, apresentam uma trilha para elaboração de estratégias pedagógicas que buscam promover a emancipação do estudante, nas esferas do desenvolvimento intelectual, liberdade de expressão e senso crítico.

O texto subsequente, o artigo original com o título $O$ uso das tecnologias da informação e comunicação na educação de jovens e adultos: uma proposta emancipadora, de autoria de Aline Carla de Sousa Leite Cipriano e Francisco Adelton Alves Ribeiro, tem como foco o uso das tecnologias da informação e comunicação (TIC's) no ensino-aprendizagem dos discentes de uma escola da rede estadual de Teresina - PI. Pautada no método do materialismo históricodialético, foi utilizado o estudo de caso com procedimento qualitativo e quantitativo para a realização da pesquisa, colhendo-se resultados por meio de informações e eventos reais, com o objetivo de descrever o contexto escolar e compreender, de modo mais amplo, seus fenômenos sociais. A partir do estudo, os pesquisadores perceberam a necessidade de a escola e os professores implementarem, de forma mais constante, as TIC's no ambiente escolar, como forma de dinamizar o ensino e aprendizagem do letramento digital, algo ainda problemático devido à carente formação de professores para o uso das tecnologias e a aparelhagem das instituições.

Por fim, o artigo original Educação ambiental e ensino de Química: estratégias para promoção da aprendizagem em EJA, dos autores Matheus Ladislau Gomes de Oliveira, José Regilmar Teixeira da Silva e Elenice Monte Alvarenga, leva em consideração as dificuldades de aprendizado dos alunos da EJA na disciplina de Química e, a partir disso, apresenta uma proposta metodológica que busca estabelecer conexões entre os conteúdos de Química e Educação Ambiental em turmas dessa modalidade de ensino. Foram aplicados questionários entre os estudantes, e os resultados obtidos impulsionaram a construção de uma proposta metodológica de ensino contextualizado, a qual, a seu fim, demonstrou que os estudantes puderam construir conhecimentos, nas áreas trabalhadas, de maneira mais efetiva.

No âmago dos textos aqui apresentados, há ponderações importantes sobre o (re)fazer docente, cabendo um diálogo com uma afirmação freiriana (da obra Pedagogia da Autonomia) que, não obstante já se tenham passado quase vinte e cinco anos, continua bastante atual: "A prática docente crítica, implicante do pensar certo, envolve o movimento dinâmico, dialético, entre o fazer e o pensar sobre o fazer." (FREIRE, 1996, p. 17).

De fato, o momento pandêmico para o qual fomos lançados, sem qualquer poder de escolha, move-nos hoje a repensar nossas estratégias didáticas (pensar sobre o fazer) e buscar soluções às desigualdades sociais que se mostram mais nítidas, sobretudo pela falta de acesso dos alunos da EJA aos meios digitais.

Assim, o compilado de textos que aqui são expostos nesta edição do primeiro semestre de 2020 da Revista EJA em Debate traz questionamentos importantes sobre o nosso fazer docente na Educação de Jovens e Adultos justamente num momento histórico em que, a despeito de nossa vontade, nossas rotinas, certezas e verdades foram... desestabilizadas.

Uma ótima leitura e profundas reflexões! 